\title{
Qualidade de vida, adesão e indicadores clínicos em pessoas vivendo com HIV
}

Quality of life, adherence and clinical indicators among people living with HIV Calidad de vida, adherencia e indicadores clínicos en personas que viven con el VIH

\author{
Marcelo Ribeiro Primeira' ${ }^{1}$ ic https://orcid.org/0000-0001-9735-6502 \\ Wendel Mombaque dos Santos ${ }^{1}$ (i) https://orid.org/0000-0002-1943-4525 \\ Cristiane Cardoso de Paula ${ }^{1}$ io hitps://orcid.org/0000-0003-4122-5161 \\ Stela Maris de Mello Padoin ${ }^{1}$ ic https://orcid.org/0000-0003-3272-054X
}

Como citar:

Primeira MR, Santos WM, Paula CC, Padoin SM. Qualidade de vida, adesão e indicadores clínicos em pessoas vivendo com HIV. Acta Paul Enferm. 2020;33:APE20190141.

http://dx.doi.org/10.37689/ acta-ape/2020A00141

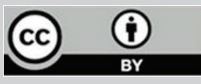

Descritores

Cuidados de enfermagem; Adesão à medicacão HIV; Infecções por HIV; Qualidade de vida

Keywords

Nursing care; Medication adherence; HIV; HIV infections; Quality of life

Descriptores

Atención de enfermeira; Cumplimiento de la medicación; VIH; Infecciones por VIH; Calidad de

Submetido 7 de Junho de 2019

Aceito

7 de Outubro de 2019

Autor correspondente

Stela Maris de Mello Padoin

E-mail: stelamaris_padoin@hotmail.com

\section{Resumo}

Objetivo: Avaliar a associação entre a qualidade de vida e a adesão ao tratamento antirretroviral.

Métodos: Estudo transversal, desenvolvido em serviço ambulatorial de doenças infecciosas em hospital universitário, localizado no interior do Rio Grande do Sul, Brasil. A amostra constitui-se de 156 participantes com HIV que responderam a questões de caracterização social, demográfica, clínica, de avaliação da adesão ao tratamento antirretroviral (CEAT-VIH), e de qualidade de vida (HAT-QoL). Foram realizadas análises estatísticas, entre elas a regressão logística para verificar associações.

Resultados: Os domínios da qualidade de vida que interferem positivamente na adesão foram os relacionados à função geral, preocupações com a medicação e confiança no profissional de saúde. 0 domínio que interferiu de forma negativa na adesão foi relacionado com as preocupações com o sigilo. Observou-se que as médias mais elevadas dos domínios de qualidade de vida estão relacionadas com a adesão estrita (adequada). A adesão estrita promove a supressão viral e 0 aumento das células de defesa no organismo. № entanto, resultados negativos nesses indicadores clínicos prejudicam os domínios de qualidade de vida, principalmente os relacionados à preocupação com a saúde, preocupações com a medicação e função sexual.

Conclusão: A qualidade de vida, associada à adesão e aos indicadores clínicos geram um ciclo, em que os diferentes resultados de cada um admitem a interferência entre si.

\section{Abstract}

Objective: To evaluate the association between quality of life and adherence to antiretroviral treatment.

Methods: Cross-sectional study conducted in an outpatient clinic for infectious disease in a university hospital located in the state of Rio Grande do Sul, Brazil. The sample consisted of 156 participants with HIV who answered questions related to social, demographic and clinical characterization, evaluation of adherence to antiretroviral treatment (CEAT-HIV), and quality of life (HAT-QoL). Statistical analyzes were performed, including logistic regression to verify associations.

Results: The quality of life domains that affect adherence positively were those related to general function, medication concerns and confidence in the health professional. The domain that affected adherence negatively was related to concerns about confidentiality. It was observed that the highest means of quality of life were associated with strict adherence (adequate). Strict adherence promotes viral suppression and increases the defense cells in the body. However, negative results in these clinical indicators impair quality of life domains, especially those related to health concerns, medication concerns, and sexual function.

Conclusion: Quality of life, associated with adherence and clinical indicators generate a cycle, in which the different results of each one suffers the interference of the others. 


\section{Resumen}

Objetivo: Evaluar la relación entre la calidad de vida y la adherencia al tratamiento antirretroviral.

Métodos: Estudio transversal, desarrollado en servicio ambulatorio de enfermedad infecciosas en hospital universitario, ubicado en el interior del estado de Rio Grande do Sul, Brasil. La muestra consistió en 156 participantes con VIH que respondieron preguntas de caracterización social, demográfica, clínica, de evaluación de adherencia al tratamiento antirretroviral (CEAT-VIH) y de calidad de vida (HAT-QoL). Se realizaron análisis estadísticos, entre ellos regresión logística para verificar relaciones.

Resultados: Los dominios de calidad de vida que interfieren positivamente en la adherencia fueron los relacionados con la función general, preocupaciones con la medicación y confianza en el profesional de la salud. El dominio que interfirió de forma negativa en la adherencia estuvo relacionado con la preocupación por el secreto profesional. Se observó que los promedios más elevados de los dominios de calidad de vida están relacionados con la adherencia estricta (adecuada). La adherencia estricta promueve la supresión viral y el aumento de las células de defensa en el organismo. Sin embargo, resultados negativos de estos indicadores clínicos perjudican los dominios de calidad de vida, principalmente los relacionados con la preocupación por la salud, preocupación por la medicación y función sexual.

Conclusión: La calidad de vida, relacionada con la adherencia e indicadores clínicos, generan un ciclo, en el cual los diferentes resultados de cada uno permiten la interferencia entre sí.

\section{Introdução}

A infecção pelo vírus da imunodeficiência humana (HIV) passa a ser considerada uma condiçáo crônica de saúde e com potencial controle endêmico a partir da implementação da terapia antirretroviral de alta atividade (TARV). ${ }^{(1)}$ Tal controle é objetivo de diretrizes nacionais e internacionais como resposta à epidemia do HIV, em que se busca alcançar a meta proposta pela Joint United Nations Program on HIVIAIDS, denominada Meta 90-90-90.(2)

Essa Meta prevê a concentração de esforços para que até 2020 cerca de $90 \%$ das pessoas infectadas pelo HIV tenham ciência do seu diagnóstico. Também, que $90 \%$ dessas estejam em tratamento com o uso de antirretrovirais (ARV) e, que $90 \%$ das pessoas que usam a TARV apresentem supressão viral que está relacionada à prevenção da transmissão do HIV. ${ }^{(2)}$

A fim de facilitar o alcance dessas metas, o Ministério da Saúde do Brasil (MS) desenvolveu o último "Protocolo Clínico e Diretrizes Terapêuticas para Manejo da Infecção pelo HIV em Adultos" de forma a oferecer conteúdo técnico e recomendaçóes atualizadas para prevenção da transmissão, tratamento da infecçáo e melhoria da qualidade de vida $(\mathrm{QV})$ das pessoas vivendo com HIV. Esse documento prevê, por meio das políticas públicas de saúde vigentes, a vinculação aos serviços de saúde, a retenção a esses serviços para o acompanhamento contínuo e a adesão ao tratamento. ${ }^{(3)}$

Visando o alcance da longevidade prevista pelo uso adequado da TARV, a adesáo ao tratamento deve manter-se adequada ao longo dos anos, resul- tando na supressão viral das pessoas vivendo com $\mathrm{HIV}^{(4-12)} \mathrm{A}$ supressão viral advinda desse tratamento deve ser concomitante ao alcance de QV semelhante às pessoas que não vivem com HIV. ${ }^{(3)}$ Dessa forma, existem condições na vida das pessoas que vivem com HIV que influenciam negativamente na QV, implicando no aumento de morbidade, mortalidade e custos. ${ }^{(9,13-15)}$

A avaliação da adesão e as possibilidades terapêuticas relacionadas à $Q V$ são indispensáveis para a criação de estratégias de tratamento em pessoas que vivem com HIV. No entanto, há escassez de evidencias na literatura que avaliem e correlacionem a qualidade de vida e a adesão ao tratamento, considerando os indicadores clínicos de supressão viral. Nesse sentido, o objetivo do estudo foi avaliar a associação entre a $\mathrm{QV}$, a adesão ao tratamento antirretroviral e a resposta dos indicadores clínicos.

\section{Métodos}

O estudo, de delineamento transversal, foi desenvolvido no ambulatório de doenças infecciosas de um hospital universitário do sul do Brasil. A populaçáo do estudo foi composta por 156 participantes com HIV, acima de 15 anos, e em TARV há pelo menos três meses. ${ }^{(3)}$

\section{Coleta de dados, instrumentos e variáveis}

A coleta de dados ocorreu entre julho de 2016 e novembro de 2017, por meio de entrevista em sala reservada. A amostra do estudo foi realizada de forma randomizada. A caracterizaçâo foi composta por dados de identificação pessoal, educacional, social, 
renda, e indicadores clínicos (Carga Viral e linfócitos TCD4+) do último exame anterior à data da entrevista. Os participantes responderam a escala para avaliação da qualidade de vida HIVIAIDS - targeted quality of life (HAT-QoL), que foi traduzida, adaptada e validada para uso no Brasil. Essa escala é composta de 34 questóes, divididas em nove domínios que contemplam funçóes gerais (FUNGER) relacionadas ao dia-a-dia, satisfação com a vida (SAVI), preocupaçóes com sua saúde (PRESA), preocupaçôes financeiras (PREFI), aceitação de sua sorologia positiva para o HIV (ACEHIV), confiança no profissional de saúde (CONPRO) e função sexual (FUSEX). A escala é do tipo likert e sua pontuação varia de 0 a 100 para cada domínio da $Q V .^{(16)} \mathrm{A}$ partir dessa pontuaçáo, optou-se por estratificar a QV como baixa quando menor que 50 pontos, e alta para domínios com 75 pontos ou mais.

Para a avaliação da adesão ao tratamento antirretroviral, foi utilizado o Cuestionario para la Evaluación de la Adhesión al Tratamiento Antiretroviral (CEAT$\mathrm{VIH})$ que foi traduzido, adaptado e validado para uso no Brasil. ${ }^{(17)} \mathrm{O}$ questionário é composto por 20 questóes que contemplam a conformidade com o tratamento, fatores que modulam a adesão, a interação entre profissional de saúde e o usuário, crenças quanto ao esforço para realizar o tratamento e avaliação dos efeitos colaterais. A pontuação é obtida pela soma dos itens, com a variação dos valores de 17 a 89 pontos. A partir dessa pontuação, o grau de adesão ao tratamento antirretroviral será classificado em "estrita", "regular" e "baixa ou inadequada adesão". ${ }^{(12)}$

\section{Análise estatística}

O banco de dados foi produzido no software Epi Info 7.0 e as análises foram executadas a partir do Software SPSS 21.0. As variáveis referentes ao questionário social e demográfico e pontuação dos domínios de QV foram descritas por meio da frequência absoluta e relativa, pela média e desvio padrão. As análises bivariadas, com objetivo de avaliar a relação entre a adesão ao tratamento e qualidade de vida, utilizaram-se dos testes Qui-quadrado ou Teste Exato de Fisher, adotando-se níveis de confiança de 95\% $(p<0,05)$. Ao avaliar a influência entre variáveis de- pendentes e independentes, foi realizada regressão linear logística e regressão binária, com Intervalo de Confiança de 95\%. Ao avaliar o impacto dos indicadores clínicos, foi utilizada regressão binária, considerando Intervalo de Confiança de 95\%.

\section{Ética}

O estudo foi aprovado pelo Comitê de Ética em Pesquisa, parecer no 1.538 .216

\section{Resultados}

A população do estudo $(n=156)$ variou entre 18 e 73 anos, com média de idade de 42,54 anos. Predominantemente do sexo feminino $(57,1 \%)$, majoritariamente da cor/raça branca $(65,4 \%)$ (preta $18,6 \%$, parda $13,5 \%$, amarela e indígena $1,3 \%$ respectivamente). Mais da metade dos participantes era residente do município sede do serviço de referência $(53,9 \%)$, conviviam com esposo(a) ou companheiro(a) (50,6\%) (solteiro(a) 25,6\%, separado(a)/ divorciado(a) 14,1\%, viúvo(a) 9,6\%) e possuíam entre 0 e 6 filhos. Quanto à escolaridade, a média de anos estudados ficou em 8,7 anos, com variação entre 0 e 16 anos estudados, com a maioria não possuindo vínculo empregatício $(60,9 \%)$ e com renda mensal entre não possuir renda e $\mathrm{R} \$ 7.000,00$, com média de R\$1.430,79. A via de infecção predominante foi a transmissão sexual $(71,2 \%)$, sendo que as demais formas de infecção pelo HIV foram de forma desconhecida $(22,4 \%)$, por drogas injetáveis $(2,6 \%)$, através de transfusão sanguínea $(1,9 \%)$ ou transmissão materna $(1,9 \%)$.

Quanto aos Indicadores clínicos, os Linfócitos TCD4+ (n=131) variaram entre 0 e 2165, com média de 537 células. A Carga Viral (cópias de HIV/ mililitro de sangue) $(\mathrm{n}=130)$ apresentou variação entre supressão viral (zero cópias) e 214.669 cópias/ milímetro de sangue, com média de 3291,39 cópias/milímetro de sangue.

$\mathrm{Na}$ avaliação da $\mathrm{QV}$, os domínios relacionados às Preocupaçóes com o sigilo (PRESI) e às Preocupaçóes financeiras (PREFI) foram os que obtiveram as menores pontuações médias indicando baixa QV, respectivamente 47,40 e 49,20 
pontos. Os domínios com maiores pontuações médias foram Satisfação com a vida (SAVI), Função sexual (FUSEX) e Preocupaçóes com a medicação (PREME), respectivamente 75,52, 80,69 e 84,20 pontos (Tabela 1).

Quanto ao grau de adesão, 1,3\% obteve baixa adesão (inadequada), 66\% apresentaram adesão insuficiente e 32,7\% adesão estrita (adequada). Dentre os valores obtidos a partir dos escores de adesão, a média foi de 81,59 pontos, o valor mínimo alcançado foi de 47 pontos, o máximo de 97 pontos e o desvio padrão foi de 8,77.

As médias mais elevadas de qualidade de vida estão relacionadas à adesão estrita (adequada), demonstrando que quanto maior o nível de QV das pessoas que vivem com HIV, maior é sua adesão ao tratamento (Tabela 1).

Ao ser avaliado o impacto dos domínios da QV junto à adesão, foi verificado que os domínios Função geral (FUNGER), Preocupaçóes com a medicação (PREME) e Confiança no profissional (CONPRO) influenciam de forma positiva a adesão, já o domínio de Preocupaçóes com o sigilo (PRESI) influência de forma negativa esse desfecho (Tabela 2).
A figura 1 demonstra a relação encontrada entre os domínios de QV que estão estatisticamente relacionadas à adesão, a influência da QV nos indicadores clínicos e a influência dos indicadores clínicos novamente na QV. Dessa forma, estar saudável indica um ciclo que não deve ser rompido na relação entre a QV e a adesão.

$\mathrm{O}$ ciclo demonstra que a adesão estrita eleva em $148 \%$ a chance de o paciente possuir CV circulante indetectável, enquanto a adesão insuficiente eleva em $74 \%$ essa chance quando comparados aos pacientes com adesão baixa. Os pacientes com adesão estrita aumentam em $225 \%$ a chance de possuírem linfócitos T-CD $4^{+}$ superiores a $500 / \mathrm{mm}^{3}$, enquanto os pacientes com adesão insuficiente aumentam em 62,5\% essa chance quando comparados aos pacientes com adesão baixa. Foi verificado o impacto dos indicadores clínicos na QV. A CV superior a 50 cópias/ml do vírus reduz de forma significativa $(p=0,05)$ em até 12,58 pontos os escores do domínio PRESA, em até 10,72 pontos os escores do domínio PREME ( $\mathrm{p}=0,01)$ e em 10,45 pontos os escores do domínio FUSEX ( $\mathrm{p}=0,05)$.

Tabela 1. Avaliação dos Escores Médios e Qualidade de vida HAT-QoL segundo o grau de adesão ao tratamento antirretroviral CEAT$\mathrm{VIH}(\mathrm{n}=156)$

\begin{tabular}{|c|c|c|c|c|c|c|c|c|}
\hline \multirow{3}{*}{ Domínio de QV } & \multirow{2}{*}{\multicolumn{2}{|c|}{ Escores Médio de QV }} & \multicolumn{6}{|c|}{ Grau de adesão } \\
\hline & & & \multicolumn{2}{|c|}{ Baixa adesão } & \multicolumn{2}{|c|}{ Adesão insuficiente } & \multicolumn{2}{|c|}{ Adesão estrita } \\
\hline & Média & DP & Média & DP & Média & DP & Média & DP \\
\hline FUNGER & 68,38 & 24,11 & 41,67 & 11,79 & 64,08 & 24,73 & 78,10 & 19,70 \\
\hline SAVI & 75,52 & 22,75 & 34,38 & 22,10 & 72,82 & 23,67 & 82,60 & 17,82 \\
\hline PRESA & 67,11 & 30,47 & 62,50 & 35,36 & 64,38 & 31,42 & 72,79 & 28,11 \\
\hline PREFI & 49,20 & 36,02 & 16,67 & 23,57 & 47,25 & 36,48 & 54,41 & 34,89 \\
\hline PREME & 84,20 & 21,23 & 50,00 & 14,14 & 81,65 & 23,45 & 90,69 & 13,00 \\
\hline ACEHIV & 64,74 & 34,45 & 31,25 & 44,19 & 62,38 & 35,33 & 70,83 & 31,59 \\
\hline PRESI & 47,40 & 31,63 & 30,00 & 42,43 & 49,17 & 31,17 & 44,51 & 32,48 \\
\hline CONPRO & 74,79 & 22,76 & 66,67 & 11,79 & 71,20 & 23,19 & 82,35 & 20,46 \\
\hline FUSEX & 80,69 & 33,91 & 12,50 & 17,68 & 79,13 & 35,67 & 86,52 & 27,14 \\
\hline
\end{tabular}

DP - desvio padrão. FUNGER: Função geral; SAVI: Satisfação com a vida; PRESA: Preocupações com a saúde; PREFI: Preocupações financeiras; PREME: Preocupações com a medicação; ACEHIV: Aceitação do HIV; PRESI: Preocupações com o sigilo; CONPRO: Confiança no profissional; FUSEX: Função sexual

Tabela 2. Influência dos domínios de qualidade de vida (HAT-QoL) na adesão ao tratamento antirretroviral (CEAT-VIH) (n=156)

\begin{tabular}{|c|c|c|c|c|c|}
\hline \multirow{2}{*}{ Domínio } & \multicolumn{2}{|c|}{ Coeficientes não padronizados } & \multirow{2}{*}{$\mathrm{t}$} & \multicolumn{2}{|c|}{ Intervalo de confiança $95 \%$} \\
\hline & B & Modelo padrão & & Limite inferior & Limite superior \\
\hline (Constante) & 58,81 & 2,95 & 19,89 & 52,97 & 64,65 \\
\hline FUNGER & 0,08 & 0,02 & 2,90 & 0,02 & 0,14 \\
\hline PREME & 0,14 & 0,03 & 4,29 & 0,08 & 0,21 \\
\hline PRESI & $-0,05$ & 0,02 & $-2,62$ & $-0,09$ & $-0,01$ \\
\hline CONPRO & 0,09 & 0,02 & 3,59 & 0,04 & 0,14 \\
\hline
\end{tabular}

FUNGER: Função geral; PREME: Preocupações com a medicação; PRESI: Preocupações com o sigilo; CONPRO: Confiança no profissional. Regressão logística 


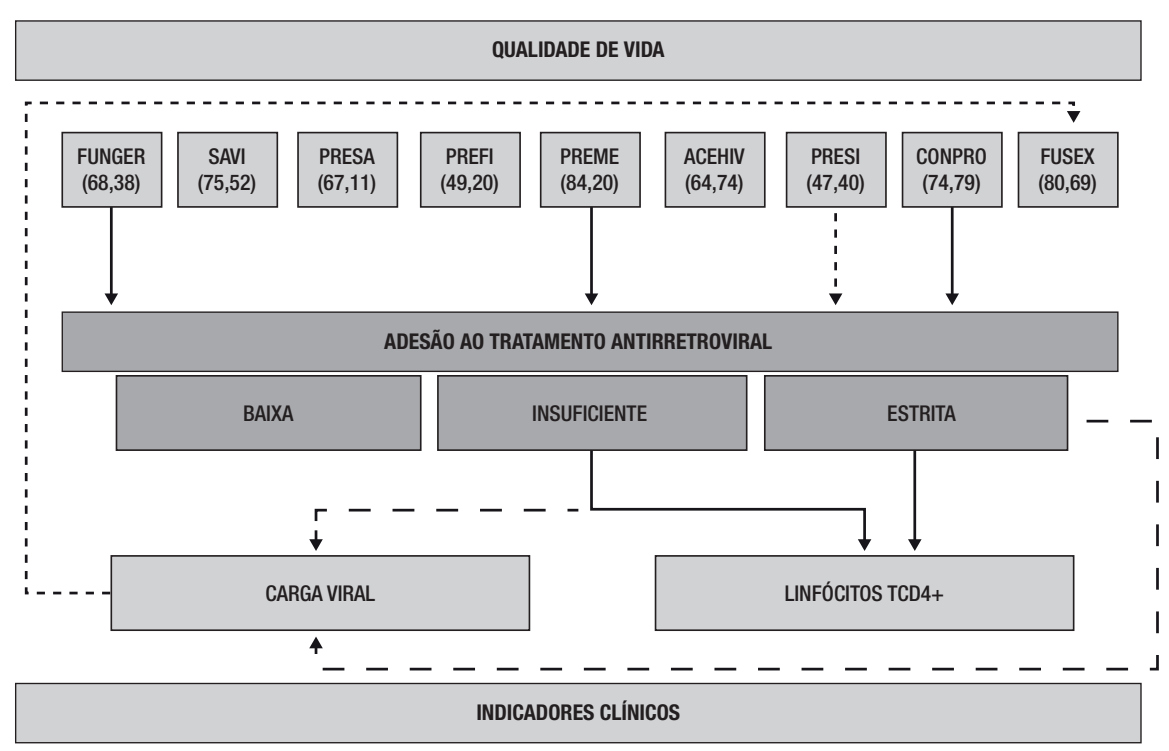

FUNGER - Função geral; SAVI - Satisfação com a vida; PRESA - Preocupações com a saúde; PREFI - Preocupações financeiras; PREME Preocupações com a medicação; ACEHIV - Aceitação do HIV; PRESI - Preocupações com o sigilo; CONPRO - Confiança no profissional; FUSEX - Função sexual

. _ _ _ _ _ Q Quando o elemento anterior interfere no valor do próximo de forma prejudicial (negativamente).

- $\rightarrow$ Quando 0 elemento anterior interfere no valor do próximo de forma a cooperar (positivamente).

$\longrightarrow$ Quando o elemento anterior eleva o valor do próximo de forma a cooperar (positivamente).

Figura 1. Ciclo da qualidade de vida de pessoas que vivem com HIV e estão em tratamento antirretroviral

\section{Discussão}

Dentre os domínios que indicaram baixa QV, a PRESI foi o que obteve a menor média. Essa preocupação se repete em diferentes contextos do Brasil, não alcançando médias com melhores escores fora do contexto nacional. ${ }^{(6,14,15,18-25)}$

A preocupação com o sigilo refere-se a não revelaçâo de diagnóstico e está relacionada, principalmente, com o estigma e a discriminação. Essa preocupação está ligada tanto a adultos com idade avançada quanto a adultos jovens. Questôes pertinentes à quebra de sigilo podem impossibilitar que o tratamento seja realizado de forma adequada quando houver medo de estigma e preconceito, comprometendo a ingestáo de doses dos ARV quando em ambientes com pessoas fora de seu convívio. A preocupação com o sigilo também está relacionada com a situação financeira mais vulnerável. ${ }^{(13,15,20)}$

O domínio PREFI promove baixa QV, sendo que fatores de vulnerabilidade social como desemprego, baixa renda e escolaridade, podem estar relacionados à queda da $\mathrm{QV}$, interferindo no investimento dos cuidados de si. . $^{(6,14,15,18-24,26)}$
Em contrapartida, o domínio SAVI obteve alta pontuação $(75,52)$, semelhante, apenas, ao escore de outros dois estudos. ${ }^{(15,22)}$ Altos escores nesse domínio podem estar associados com o vínculo empregatício ou a aposentadoria (renda fixa), além disso, pode estar associado a maiores condiçóes de desfrutar a vida, sentindo-se no controle dela, utilizando do trabalho, muitas vezes, como momento de socialização. ${ }^{(15,20)}$

$\mathrm{O}$ domínio que abrange a função sexual (FUSEX) obteve bons resultados na pesquisa em tela $(80,69)$. Isso demonstra que ter vida sexualmente ativa é importante para que esse domínio tenha bons escores, da mesma forma que ter um parceiro fixo ou ser casado. O risco de transmissão do vírus faz com que as pessoas com HIV tenham medo de se relacionar sexualmente. Além da preocupação em transmitir o vírus, esse domínio pode estar prejudicado pela falta de confiança e dificuldade em negociar o uso de preservativo com seu parceiro. ${ }^{(19)}$

Quanto ao domínio que corresponde à preocupação com a medicaçáo (PREME), em território nacional tiveram variação de 79,80 a 88,72 pontos. (15,19,20,24) Pesquisas internacionais também obtive- 
ram escores altos no Zimbábue $(86,70)$ e na Índia $(91,38) .{ }^{(14,25)}$ Os participantes da pesquisa consideravam, nesse domínio, que o uso dos ARV despendia pouco tempo para sua ingestão e não apresentavam efeitos colaterais intensos que pudessem interferir na sua rotina diária.

Os achados evidenciam que a QV deve estar em constante avaliação de modo que, apesar de não haver padronização dos escores verificados em todas as pesquisas citadas, tanto nacional quanto internacionalmente, os domínios com abrangência de preocupaçóes financeiras e de quebra de sigilo foram observados em praticamente todos os estudos. ${ }^{(6,14,15,18-26)}$

Quanto à avaliação de adesão, observa-se certa variação nos resultados de adesão estrita, o que mostra a diversidade entre os serviços e amostras populacionais nos diferentes estados do País. ${ }^{(4-6,9,10,27)}$ Isso leva-nos a refletir que, apesar da política de saúde para o tratamento ser a mesma para todo território nacional, a estrutura dos serviços de um modo amplo, bem como questóes culturais das populaçóes estudadas, pode intervir para que não haja um padrão de adesão ao tratamento.

Da mesma forma que o Brasil, outros países também utilizaram o CEAT-VIH para avaliar e classificar a adesão ao tratamento, no entanto, nenhum outro estudo internacional ultrapassou os $32 \%$ de adesão estrita encontrado nesta pesquisa. ${ }^{(7,8,11,12)}$ Esse resultado é reflexo do sistema de saúde do Brasil e sua política universal de controle da epidemia do HIV.

Estudos brasileiros que utilizaram a escala de avaliação de QV da OMS e a escala da adesão por meio do CEAT-HIV apresentaram correlaçóes estatisticamente significativas entre as variáveis dessas escalas. Houve relação entre os domínios referentes às questôes física, espiritual, psicológica, nível de independência, relaçóes sociais e o ambiente. Isso demonstrou que esses domínios têm contribuição na adesão ao tratamento para pessoas vivendo com HIV. E, que as pessoas com não adesão apresentam os piores escores médios para a $\mathrm{QV} .^{(9,12,28,29)}$

As evidências que suportam os domínios relativos à preocupação com a medicação (PREME) e a confiança no profissional (CONPRO), relacionadas à QV, foram estatisticamente significativas quando correlacionadas com a pontuação de adesão, ${ }^{(24)}$ corroborando os achados deste estudo.

Portanto, os profissionais de saúde devem ter conhecimento da avaliação da QV de seus usuários, de forma a compreenderem os aspectos da QV que interferem na adesão. Como resultado favorável da adesão ao tratamento, se observará melhora das condiçôes clínicas do paciente, aumento de linfócitos T-CD4+ e redução (supressão) da CV, que resultarão em efeitos positivos na $\mathrm{QV}$. $^{(6)}$

O profissional de saúde deve estar preparado para intervir, quando possível, junto aos domínios mais comprometidos de qualidade de vida. Assim, o estigma e preconceito podem ser trabalhados em equipe, e os problemas financeiros, ou medos relacionados à renda limitada que estas pessoas podem estar sujeitas, podem ser analisados e esclarecidos por outros profissionais como o assistente social. Essas avaliaçóes e encaminhamentos podem ser realizadas pelo enfermeiro.

Outra recomendação refere-se à necessidade de promover o vínculo entre profissional e usuário e que se traduz em confiança imprescindível para o sucesso do tratamento, uma vez que poderá refletir em aceitação dos cuidados prescritos. Atrelado à aceitação da prescrição e ao vínculo com o profissional de saúde, está o uso correto dos ARV.

A avaliação da qualidade de vida e da adesão podem ser incorporadas na atenção à saúde dessa população. A QV pode ser verificada antes mesmo do início da terapia, promovendo cuidados específicos em domínios que podem vir a ser preditoras de não adesão. Sua avaliação deve ser contínua, assim como a adesão, da mesma forma que os exames laboratoriais que são instituídos como rotina.

Como limitaçôes deste estudo, a avaliação em um único momento (transversal) sem a possibilidade de intervir nos pontos avaliados.

\section{Conclusão}

Os resultados deste estudo evidenciam que a qualidade de vida de pessoas com HIV fica comprometida, principalmente, pela preocupação com o 
sigilo e preocupação financeira. Em contrapartida, a confiança no profissional é promotora de adesão, colaborando para a melhora da condição de vida das pessoas que vivem com HIV. Também ficou evidente que valores de carga viral maiores de 50 cópias por decímetro cúbico de sangue, comprometem domínios da qualidade de vida. E que a relação da qualidade de vida com a adesão promove bons resultados clínicos.

\section{Agradecimentos}

Ao Hospital Universitário de Santa Maria em nome da Universidade Federal de Santa Maria e seus respectivos usuários do Sistema Único de Saúde. Aos Programas Institucionais de Bolsas de Iniciação Científica (PIBIC/CNPq, PROIC/ HUSM, PROBIC/FAPERGS). Ao Conselho Nacional de Ciência e Tecnologia (CNPq; Bolsista de Produtividade em Pesquisa - Nível 1D; Stela Maris de Mello Padoin); Chamada: Universal 2016. Número do Processo: 408709/20162. Título do Projeto: Adesão ao Tratamento Antirretroviral do HIV: intervenção e controle. À Coordenação de Aperfeiçoamento de Pessoal de Nível Superior (CAPES; Bolsista do Programa de Demanda Social; Marcelo Ribeiro Primeira).

\section{Colaborações}

Primeira MR, Santos WM, Padoin SMM e Paula CC declararam que participaram da concepção do estudo, análise e interpretação dos dados, redação do manuscrito, revisão crítica do conteúdo e aprovação da versão final a ser publicada.

\section{Referências}

1. Mendes EV. A construção social da atenção primária à saúde. Brasília (DF): Conselho Nacional de Secretários de Saúde - CONASS; 2015. 193p.

2. Unaids. Ending AIDS. Progress towards the 90-90-90 targets. Global Aids Update [nternet]. Joint United Nations Programme on HIV/AIDS; 2017. [cited 2019 Sep 25]. Available from: https://www.unaids.org/ sites/default/files/media_asset/Global_AIDS_update_2017_en.pdf
3. Brasil. Ministério da Saúde. Protocolo Clínico e Diretrizes Terapêuticas para Manejo da Infecção pelo HIV em Adultos. Secretaria de Vigilância em Saúde. Departamento de Vigilância, Prevenção e Controle das Infecções Sexualmente Transmissíveis, do HIV/Aids e das Hepatites Virais. Brasília (DF); 2017. 416 p.

4. Zuge SS, Primeira MR, Remor E, Magnago TS, Paula CC, Padoin SM. Fatores associados à adesão ao tratamento antirretroviral em adultos infectados pelo HIV: estudo transversal. Rev Enferm UFSM. 2017;7(4):577-89.

5. Dagli-Hernandez C, Lucchetta RC, de Nadai TR, Galduróz JC, Mastroianni PC. Self-perception of knowledge and adherence reflecting the effectiveness of antiretroviral therapy. Patient Prefer Adherence. 2016;10:1787-93.

6. Liping M, Peng X, Haijiang L, Lahong J, Fan L. Quality of Life of People Living with HIV/AIDS: A Cross-Sectional Study in Zhejiang Province, China. PLoS One. 2015;10(8):e0135705.

7. Salmanton-García J, Herrador Z, Ruiz-Seco P, Nzang-Esono J, Bendomo V, Bashmakovic E, et al. Self-reported adherence to antiretroviral therapy in HIV+ population from Bata, Equatorial Guinea. AIDS Care. 2016;28(5):543-53.

8. Tello-Velásquez JR, Díaz-Llanes BE, Mezones-Holguín E, RodríguezMorales AJ, Huamaní C, Hernández AV, et al. La mala calidad de sueño se asocia a una menor adherencia al tratamiento antirretroviral de gran actividad en pacientes peruanos con infección por VIH/SIDA. Cad Saude Publica. 2015;31(5):989-1002.

9. Silva AC, Reis RK, Nogueira JA, Gir E. Quality of life, clinical characteristics and treatment adherence of people living with HIV/ AIDS. Rev Lat Am Enfermagem. 2014;22(6):994-1000.

10. Moraes DC, Oliveira RC, Costa SF. Adesão de homens vivendo com HIV/ Aids ao tratamento antirretroviral. Esc Anna Nery. 2014;18(4):676-81.

11. Dima AL, Schweitzer AM, Diaconiţ R, Remor E, Wanless RS. Adherence to ARV medication in Romanian young adults: self-reported behaviour and psychological barriers. Psychol Health Med. 2013;18(3):343-54.

12. Remor E. Self-reported adherence to antiretroviral therapy in HIV+ Colombian Population. SAGE Open, 2013;3(3):1-7.

13. Jesus GJ, Oliveira LB, Caliari JS, Queiroz AA, Gir E, Reis RK. Dificuldades do viver com HIV/Aids: entraves na qualidade de vida. Acta Paul Enferm. 2017;30(3):301-7.

14. Mafirakureva N, Dzingirai B, Postma MJ, van Hulst M, Khoza S. Healthrelated quality of life in HIV/AIDS patients on antiretroviral therapy at a tertiary care facility in Zimbabwe. AIDS Care. 2016;28(7):904-12.

15. Soares GB, Garbin CA, Rovida TA, Garbin AJ. Qualidade de vida de pessoas que vivem com HIV/AIDS assistidas no serviço especializado em Vitória (ES), Brasil. Ciênc Saúde Coletiva. 2015;20(4):1075-84.

16. de Soárez PC, Castelo A, Abrão P, Holmes WC, Ciconelli RM. Tradução e validação de um questionário de avaliação de qualidade de vida em AIDS no Brasil. Rev Panam Salud Publica. 2009;25(1):69-76.

17. Remor E, Milner-Moskovics J, Preussler G. Adaptação brasileira do "Cuestionario para la Evaluación de la Adhesión al Tratamiento Antiretroviral”. Rev Saude Publica. 2007;41(5):685-94.

18. Biambo AA, Adibe MO, Liman HM, Ukwe CV. Health-related quality of life of HIV-infected patients taking different antiretroviral regimens at a tertiary healthcare facility in northern Nigeria. Trop J Pharm Res. 2018;17(3):549-57.

19. Caliari JS, Reinato LA, Pio DP, Lopes LP, Reis RK, Gir E. Qualidade de vida de idosos vivendo com HIV/aids em acompanhamento ambulatorial. Rev Bras Enferm. 2018;71 Supl 1:556-65. 
20. Cesnales NL, Thyer BA, Albright DL. Differences in health-related quality of life among persons living with HIV/AIDS. J Hum Behav Soc Environ. 2017;27(3):198-205.

21. Medeiros RC, Medeiros JA, Silva TA, Andrade RD, Medeiros DC, Araújo JS, et al. Qualidade de vida, fatores socioeconômicos e clínicos e prática de exercício físico em pessoas vivendo com HIV/Aids. Rev Saude Publica. 2017;51:66.

22. Okuno MF, Gosuen GC, Campanharo CR, Fram DS, Batista RE, Belasco AG. Quality of life, socioeconomic profile, knowledge and attitude toward sexuality from the perspectives of individuals living with Human Immunodeficiency Virus. Rev Lat Am Enfermagem. 2015;23(2):192-9.

23. Silveira MP, Silveira MF, Müller CH. Quality of Life of Pregnant Women Living with HIV/AIDS. Rev Bras Ginecol Obstet. 2016;38(5):246-52.

24. Galvão MT, Soares LL, Pedrosa SC, Fiuza ML, Lemos LA. Fiuza ML, Lemos LA. Qualidade de vida e adesão à medicação antirretroviral em pessoas com HIV. Acta Paul Enferm. 2015;28(1):48-53.
25. Shenoy A, Ramapuram JT, Unnikrishan B, Achappa B, Madi D, Rao S, et al. Effect of Lipodystrophy on the Quality of Life among People Living with HIV (PLHIV) on Highly Active Antiretroviral Therapy. J Int Assoc Provid AIDS Care. 2014;13(5):471-5.

26. Fekete EM, Williams SL, Skinta MD, Bogusch LM. Gender differences in disclosure concerns and HIV-related quality of life. AIDS Care. 2016;28(4):450-4.

27. Casotti JA, Passos LN, Oliveira FJ, Cerutti C Jr. Factors associated with paradoxical immune response to antiretroviral therapy in HIV infected patients: a case control study. BMC Infect Dis. 2011;11(1):306.

28. Dasgupta P, Mukhopadhyay S, Saha D. Assessment of quality of life among human immunodeficiency virus/Acquired immuno deficiency syndrome patients: A study at antiretroviral therapy center at Malda, West Bengal, India. Arch Med Health Sci. 2018;6(2):208.

29. Calvetti PÜ, Giovelli GR, Gauer GJ, Moraes JF. Psychosocial factors associated with adherence to treatment and quality of life in people living with HIV/AIDS in Brazil. J Bras Psiquiatr. 2014;63(1):8-15. 